\title{
Exploring Nursing Students' Learning Experiences in Improving Their Health Information Technology Competency in Interdisciplinary Cooperation: An Innovative Pilot Study
}

\author{
Hsieh CHIA-JUNG ${ }^{\mathrm{a}, 1}$, Hsu TZU-CHI ${ }^{\mathrm{b}}$ and Hsu PEI-CHANG ${ }^{\mathrm{c}}$ \\ ${ }^{a}$ Department of Nursing, National Taipei University of \\ Nursing and Health Sciences, Taiwan, ROC \\ ${ }^{\mathrm{b}}$ Department of Computer Science and Information Enginerring, \\ National Ilan University, Taiwan, ROC \\ ${ }^{\mathrm{c}}$ Pacy Tech Service Inc., Taiwan, ROC
}

\begin{abstract}
This study aims to explore nursing students' learning experiences in improving their health information technology competency in interdisciplinary cooperation. Through the nursing student training for designing thinking focused on smart health, we revealed the profound learning experience through interdisciplinary cooperation as well as the practice of problem solving, not only strengthens the students' health information technology competency, but ignites their creative thinking and creativity, altogether enhances their competitiveness in health care industry.
\end{abstract}

Keywords. Health information technology competency, interdisciplinary cooperation, home care management, cooperative learning

\section{Introduction}

Interdisciplinary teamwork cooperation has been recognized as a model in the health care professional development. Interdisciplinary collaboration is commonly described using the terms problem-focused process, sharing, and working together [1]. Improving information technology (IT) competency of nursing students and bridging digital divide is beneficial to improve the quality of IT implementation in health care delivery.

Effective collaboration within nursing education and with other healthcare professionals to achieve quality outcomes in education is importance [2].

${ }^{1}$ Corresponding Author, Hsieh Chia-Jung, No. 365, Ming-te Road, Peitou District, Taipei City, 11219, Taiwan, ROC; E-mail: chiajung@ntunhs.edu.tw. 


\section{Purpose}

This study aims to explore nursing students' learning experiences in improving their health information technology competency in interdisciplinary cooperation.

\section{Methods}

Here we introduce an innovative interdisciplinary program through IT integration into program curricula. Research subjects, i.e., the third-year students in the on-the-job training program, were guided to brainstorm the application of IT in home care management. Teaching strategies such as interactive teaching, simulation, and role play were implemented to facilitate the brainstorming, and to evolve a feasible strategy. The final results of cooperative learning were presented by qualitative data analysis.

\section{Results}

Five themes identified via qualitative data of 14 students (13 females and 1 male) were as follows.1. Relieve the anxiety about IT software application. 2. Recognize the necessity of communication. 3. Integrate the concept of design thinking and profession. 4. Match the user's need. 5. Affirm the significance of the prototypes (Figure 1).

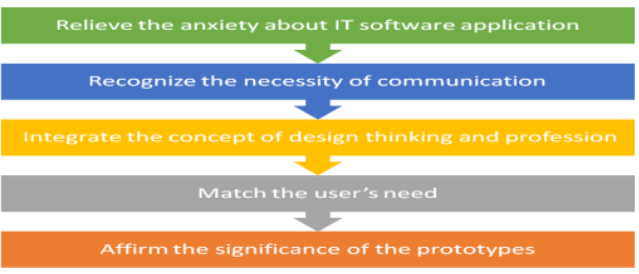

Figure 1. Research themes

\section{Conclusion}

Through the nursing student training for designing thinking focused on smart health, we revealed the profound learning experience through interdisciplinary cooperation as well as the practice of problem solving, not only strengthens the students' health information technology competency, but ignites their creative thinking and creativity, altogether enhances their competitiveness in health care industry.

\section{Acknowledgements}

We thank all the subjects for their valuable experience and the real feedback from the elders living in the senior housing. 


\section{References}

[1] Petri L. (2010). Concept analysis of interdisciplinary collaboration. Nursing Forum, 45(2), 73-82.

[2] Rakhudu MA, Davhana-Maselesele M, Useh U. (2016). Concept analysis of collaboration in implementing problem-based learning in nursing education. Curationis, 39(1), e1-e13. doi: 10.4102/curationis.v39i1.1586 